\title{
Discriminant value of psychological distress, symptom profiles, and segmental colonic dysfunction in outpatients with severe idiopathic constipation
}

\author{
R L Grotz, J H Pemberton, N J Talley, D M Rath, A R Zinsmeister
}

\begin{abstract}
Severe idiopathic constipation can be categorised based on physiological testing into subgroups including slow transit constipation and pelvic floor dysfunction. This study aimed to determine if colonic and psychological symptoms, or rectosigmoid transit times, could discriminate among these subgroups. Patients, categorised according to total colonic transit times and pelvic floor function testing, completed a self report questionnaire that recorded symptoms and psychological distress. Patients with normal transit constipation $(n=60)$ had significantly increased depression scores compared with those who had slow transit constipation $(n=70)$ or pelvic floor dysfunction $(n=30)$. The general severity index (GSI, a measure of overall psychological distress) negatively but weakly correlated with total colonic transit $(r=-0 \cdot 26, p<0 \cdot 01)$. A feeling of anal blockage was the only symptom that was associated with pelvic floor dysfunction ( $v$ normal transit constipation). Only a more regular defecation pattern, utilisation of different postures to defecate, and a feeling of incomplete evacuation were associated with slow $v$ normal transit constipation. Psychological or colonic symptoms were not, however, significant discriminators in a multivariate analysis. Rectosigmoid transit times at $\mathbf{8 0} \%$ sensitivity had very poor specificity for discriminating pelvic floor dysfunction from other subgroups. It is concluded that clinical symptoms, psychological distress, and rectosigmoid transit times cannot be used to identify subgroups of patients with intractable constipation.

(Gut 1994; 35: 798-802)
\end{abstract}

Symptoms of constipation are reported by about $20 \%$ of the general population. ${ }^{1}$ Intractable unexplained constipation, which is much less common, primarily affects young and middle aged women who often eventually present to tertiary referral centres for treatment. $^{2}$ Physiological testing has been considered necessary to discriminate among subgroups of patients with severe constipation. Thus, based on objective assessment of colonic transit and pelvic floor function, patients with chronic unexplained constipation can be subdivided into four groups: those who have slow transit constipation, pelvic floor dysfunction, combined slow transit constipation and pelvic floor dysfunction, or normal colonic transit and normal pelvic floor function (referred to here as normal transit constipation). ${ }^{3}$

The role of psychological factors in the pathophysiology of severe chronic constipation is unclear. Personality may influence stool weight and frequency, 4 and a coexisting psychiatric disorder is common in patients with functional bowel disorders. ${ }^{56}$ Furthermore, when compared with patients with slow transit constipation, those with normal transit constipation have shown greater psychological distress in two studies. ${ }^{78}$ These investigations, however, were all based on small samples of referred patients and, thus, it is still uncertain if psychological distress can discriminate between physiological subgroups of patients with severe intractable constipation in a useful way. Furthermore, no studies have evaluated the discriminant value of colonic symptoms in identifying subgroups of constipation.

A radio-opaque marker study is an inexpensive and reproducible test of colonic transit. ${ }^{9} 10$ Colonic transit times are used to assess the severity of constipation and the distribution of the markers in the colonic segments provides data about regional function. While a disturbance in the mechanics of defecation may delay transit through one or more segments, the discriminatory value of segmental delay (for example, in the rectosigmoid in pelvic floor dysfunction) likewise remains unclear. ${ }^{10-12}$

Our objectives were to determine if psychological and clinical symptoms accurately distinguish between patients with slow transit constipation, pelvic floor dysfunction, and normal transit constipation. We postulated that a self administered questionnaire could serve to categorise patients diagnostically, thus perhaps avoiding extensive physiological testing. Surveys have been used with reasonable success in the assessment of other functional bowel diseases. ${ }^{13-18} \mathrm{~A}$ questionnaire that assesses, and possibly distinguishes, between subgroups of severe constipation would be particularly useful.

\section{Methods}

\section{SUBJECTS}

The study was approved by the Institutional Review Board of the Mayo Clinic. The records 
of all patients referred to the Mayo Clinic for evaluation of severe idiopathic constipation in the years 1987 to 1990 were reviewed. Only patients with constipation who had been refractory to conservative and medical management were included. Constipation was operationally defined as less than three stools per week or excessive straining at defecation. Patients with metabolic (drug induced, endocrine) and structural (tumour, stricture, neurological) causes of constipation were excluded. Informed consent was obtained from each participant.

All patients had an in depth interview of bowel habits by a nurse specialist and physical examination, which included digital rectal examination and proctoscopy. A colonic transit study was required for inclusion in the study. Physiological assessment of pelvic floor function was performed if any symptoms suggested outlet delay (obstructed defecation) or if total colonic transit was prolonged, as described below. Based on independent detailed physiological investigations, patients were thus categorised as having: (a) slow transit constipation, (b) pelvic floor dysfunction, (c) combined slow transit constipation/ pelvic floor dysfunction, or (d) normal transit constipation.

\section{PHYSIOLOGICAL METHODS}

Measurement of colonic transit time - the colonic transit study was performed using a previously validated technique. ${ }^{9}$ Patients were asked to maintain their usual diet and avoid laxatives for the duration of the study. Subjects ingested 20 radio-opaque markers (size: $1.0 \mathrm{~mm} \times 4.5$ mm; Sitzmarks Lafayette Pharmacol, Fort Worth, TX) at 900 am on three consecutive days. An abdominal $x$ ray was obtained on the fourth study day at 800 am using a high kilovoltage fast film technique to reduce the amount of radiation exposure (estimated surface exposure $=0.08 \mathrm{mrad} /$ film). A second abdominal $x$ ray was taken on the seventh study day at $800 \mathrm{am}$. The upper limit of normal for total colonic transit time was set at 72 hours; this value was obtained by estimating the 95th percentile for transit times in a sample of healthy subjects. ${ }^{9}$ The radio-opaque marker method has been validated at Mayo Clinic against scintigraphy in health ${ }^{19}$ and in chronic idiopathic constipation. ${ }^{20}$

Measurement of pelvic floor function - pelvic floor studies were obtained in all patients if the colonic transit time exceeded 72 hours or if patients had one or more of the following complaints: difficulty or painful emptying of stool, or both, prolonged defecation, contortions while defecating, finger digitation of the anal canal, perineal increase, or a sensation of fullness or incomplete emptying. Tests of pelvic floor function were considered abnormal if: (1) the patient could not pass a rectal balloon spontaneously or needed more than $100 \mathrm{~g}$ of weight to pull the balloon past the pelvic outlet; or (2) the anorectal angle did not become obtuse upon defecation or if the pelvic floor did not descend on defecation; or (3) the rectal emptying study was less than $40 \% .^{3} 11$ Segmental colonic transit times and data from the self-report questionnaire were not used to classify the patients.

\section{SURVEY METHODS}

All study subjects were mailed a questionnaire with a letter explaining the study and requesting their participation. Additional questionnaires with a reminder letter were sent to non-responders three, six, and nine weeks after the first mailing. After 12 weeks, the remaining non-responding subjects were telephoned by the investigator and personally interviewed when possible.

Measurement of gastrointestinal symptoms - a self administered questionnaire was developed to measure gastrointestinal symptoms. The survey was based upon the bowel disease questionnaire, which has previously been shown to be reliable and valid in studying outpatient populations. ${ }^{1415}$ Subjects were instructed to answer all questions relating to symptoms within the past year only. If the subjects had had subtotal colectomy and ileorectostomy for slow transit constipation or pelvic floor retraining for pelvic floor dysfunction, the subjects were instructed to answer questions pertaining to symptoms during the year before therapeutic intervention. The survey was assembled using questions that included gastrointestinal, colonic, and anorectal symptoms. The questionnaire used in this study comprised 58 symptom items, five childhood questions, and 15 past and present health items. Questions pertaining to constipation, obstructed defecation, and past medical or surgical problems related to gastrointestinal symptoms were included. The instrument was pretested by giving the questionnaire by interview to 33 patients and then retesting with a self administered mailed questionnaire two weeks later.

Measurement of psychological distress - the self administered questionnaire measured psychological distress using the valid brief symptom inventory (BSI). This is a shortened version of the Hopkins symptom checklist (SCL-90-R), which has been used previously to evaluate constipated patients. ${ }^{7}$ This instrument consists of 53 questions, which measure distress for each item based on a 5 point scale. The instrument is scored for nine clinical subscales (obsessive-compulsion, somatisation of affect, depression, interpersonal sensitivity, phobic anxiety, hostility, anxiety, psychoticism, and paranoid ideation). The general severity index (GSI) represents the overall level of psychological distress. Permission for use of this instrument was obtained from Clinical Psychometric Research, Inc (copyright: Leonard R Derogatis, $\mathrm{PhD}$, Riderwood, $\mathrm{MD}$ ).

Survey - a total of 330 patients had a diagnosis of chronic idiopathic constipation; patients with reported structural causes for constipation or intestinal pseudo-obstruction were not considered. Excluded were five subjects who had died, two with dementia, two with legal problems, and three who were 
TABLE I Psychological distress and subgroups of constipation ( $n=184)$. Median (25th and 75th percentiles)

\begin{tabular}{|c|c|c|c|c|c|}
\hline & $\begin{array}{l}\text { Slow transit constipation } \\
(n=70)\end{array}$ & $\begin{array}{l}\text { Pelvic floor dysfunction } \\
(n=30)\end{array}$ & $\begin{array}{l}\text { Slow transit and pelvic } \\
\text { floor dysfunction } \\
(n=24)\end{array}$ & $\begin{array}{l}\text { Normal transit } \\
\text { constipation } \\
(n=60)\end{array}$ & $\begin{array}{l}\text { Overall } \\
\text { comparison } \\
p\end{array}$ \\
\hline $\begin{array}{l}\text { Female (\%) } \\
\text { Age (y) }\end{array}$ & $\begin{array}{l}94 \\
45(34,59)\end{array}$ & $\begin{array}{l}93 \\
44(33,56)\end{array}$ & $\begin{array}{l}92 \\
41(32,50)\end{array}$ & $\begin{array}{l}75 \\
48(38,68)\end{array}$ & $\begin{array}{l}\mathrm{p}<0 \cdot 01^{\star \star} \\
\mathrm{NS}\end{array}$ \\
\hline \multicolumn{6}{|l|}{ Scoret } \\
\hline $\begin{array}{l}\text { Somatisation } \\
\text { Depression }\end{array}$ & $0.57(0.14,1 \cdot 14)$ & $\begin{array}{l}0.50(0.29,1 \cdot 0) \\
0.33(0.0 .83)\end{array}$ & $\begin{array}{l}0.50(0.07,1.21) \\
0.17(0,0.75)\end{array}$ & $\begin{array}{l}0.86(0.43,1.17) \\
0.75(0.17,1.50)\end{array}$ & $\begin{array}{l}\text { NS } \\
\mathfrak{p}<0.05\end{array}$ \\
\hline $\begin{array}{l}\text { Depression } \\
\text { Anxiety }\end{array}$ & $0.50(0.17,1.0)$ & $0.33(0.17,0.67)$ & $0.58(0.08,0.83)$ & $0.67(0.25,1.0)$ & $\begin{array}{l}\mathrm{p}<\mathrm{NS} \\
\mathrm{NS}\end{array}$ \\
\hline Phobic anxiety & $0(0,0 \cdot 20)$ & $0(0,0 \cdot 20)$ & $0(0,0 \cdot 10)$ & $0.20(0,0.60)$ & $p=0.06$ \\
\hline Obsessive-compulsive & $0.67(0.33,1.17)$ & $0.58(0.17,1.33)$ & $0.25(0,0.92)$ & $0.83(0.42,1.50)$ & $p=0.05$ \\
\hline Interpersonal sensitivity & $0.50(0,0.75)$ & $0.25(0,1 \cdot 25)$ & $0.25(0,0.50)$ & $0.50(0.25,1.38)$ & $p=0.06$ \\
\hline Hostility & $0.30(0.20,0.80)$ & $0.40(0.20,0.60)$ & $0.20(0,0.60)$ & $0 \cdot 40(0 \cdot 20,0 \cdot 80)$ & NS \\
\hline Paranoid ideation & $0 \cdot 20(0,0 \cdot 60)$ & $0.20(0,0.75)$ & $0(0,0 \cdot 50)$ & $0.40(0,0.80)$ & NS \\
\hline Psychoticism & $0.20(0,0.60)$ & $0(0,0 \cdot 20)$ & $0(0,0.70)$ & $0.20(0,0.60)$ & NS \\
\hline General severity index & $0.43(0.26,0.81)$ & $0.33(0.23,0.89)$ & $0 \cdot 30(0 \cdot 16,0 \cdot 75)$ & $0.58(0.36,0.99)$ & $\mathrm{p}<0.05$ \\
\hline
\end{tabular}

${ }^{\star}$ Results of one way Kruskal-Wallis (non-parametric) comparison of all four groups (NS $=$ not significant); ${ }^{\star \star} \chi^{2}$ test for contingency table of sex by diagnosis; †raw scores from the brief symptom inventory.

Pairwise comparisons at $\alpha=0.017$ to adjust for three pairwise comparisons (excluding slow transit and pelvic floor dysfunction combined group): normal transit constipation $v$ pelvic floor dysfunction - only depression significant. Normal transit constipation $v$ slow transit constipation - only depression significant. All other comparisons - none of the scores significant. Pairwise comparisons at $\alpha=0.008$ to adjust for six pairwise comparisons (including slow transit and pelvic floor dysfunction combined group): normal transit constipation $v$ slow transit and pelvic floor dysfunction combined: only obsessive-compulsive significant (no other comparisons were significant).

inmates at a local Federal Medical prison. In addition, 27 who did not receive colonic transit testing were excluded. Thus, the survey was mailed to 291 eligible patients. Forty six subjects refused to complete the questionnaire and 51 subjects could not be contacted despite repeated attempts. One hundred and ninety four patients $(67 \%$ of those eligible) returned the survey; of these, 10 patients returned incompleted surveys and so were subsequently excluded. The final study population thus comprised 184 patients with chronic idiopathic constipation who had completed a questionnaire and physiological studies.

\section{STATISTICAL ANALYSIS}

Comparisons of segmental colonic transit times and psychometric scores among all patient subgroups were assessed using a non-parametric (Kruskal-Wallis) rank test. Pair wise comparisons were then performed using a Wilcoxon rank sum test (slow transit constipation $v$ normal transit constipation, pelvic floor dysfunction $v$ normal transit constipation, and pelvic floor dysfunction $v$ slow transit constipation); the $\alpha$ value was set at $0 \cdot 017$ to adjust for

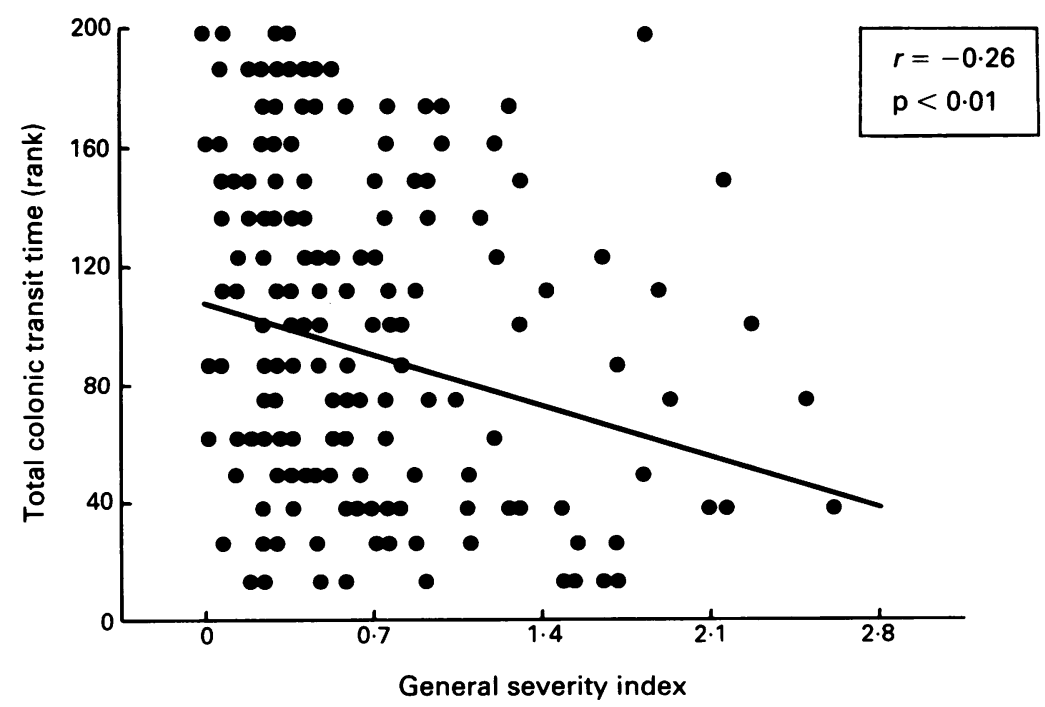

Correlation between overall psychological distress and total colonic transit time in the study population ( $n=184$ ) (note: some points represent multiple values). three comparisons. Linear regression analysis was used to assess the association between total colonic transit times (ranks) and psychometric scores (the general severity index). Finally, logistic regression analysis was used to identify the psychometric scores and symptom items that would separately discriminate slow transit constipation $v$ normal transit constipation, pelvic floor dysfunction $v$ normal transit constipation, and slow transit constipation $v$ pelvic floor dysfunction, adjusting initially for age and sex and, in separate models, for segmental transit times.

\section{Results}

Of the 184 patients studied, most (87.5\%) were women, and the mean age was 45 years (interquartile range 34-59). Among these patients, 70 were classified as slow transit constipation, 30 pelvic floor disorder, 24 both slow transit and pelvic floor disorder, and 60 normal transit constipation (Table I). Patients with both slow transit constipation and pelvic floor dysfunction were not considered in the primary analyses.

\section{PSYCHOLOGICAL DISTRESS}

Table I summarises the distributions of the BSI scores in each of the subgroups. The GSI showed a weak, negative correlation with total colonic transit $(r=-0.26, p<0.01)$, and the overall $r^{2}$ value was only 0.09 (Figure). Of the nine subscales, depression and the GSI scales were significantly different among the four groups, although differences in phobic anxiety, obsessive-compulsive, and interpersonal sensitivity were of borderline significance (Table I). Adjusting for three multiple comparisons, only depression scores were significantly higher in patients with normal transit constipation compared with pelvic floor dysfunction and, separately, slow transit constipation. No significant differences were detected between slow transit constipation and pelvic floor dysfunction.

COLONIC SYMPTOMS

Table II summarises the distribution of the colonic and anorectal symptoms in each 
TABLE II Distribution of colonic and rectal symptoms in subgroups of constipation

\begin{tabular}{|c|c|c|c|c|}
\hline Symptoms & $\begin{array}{l}\text { Slow transit } \\
\text { constipation } \\
(n=70)\end{array}$ & $\begin{array}{l}\text { Pelvic floor } \\
\text { dysfunction } \\
(n=30)\end{array}$ & $\begin{array}{l}\text { Slow transit } \\
\text { and pelvic floor } \\
\text { dysfunction } \\
(n=24)\end{array}$ & $\begin{array}{l}\text { Normal transit } \\
\text { constipation } \\
(n=60)\end{array}$ \\
\hline Number of days without a bowel movement (median, IQR) & $10(5,15)$ & $7(2,9)$ & $12(7,14)$ & $7(3,14)$ \\
\hline Stool frequency $\leqslant 2 /$ week $(\%)$ & 54 & 40 & 67 & 38 \\
\hline Constipation affects lifestyle (\%) & 69 & 70 & 71 & 73 \\
\hline Laxative dependent (\%) & 44 & 33 & 58 & 48 \\
\hline Enema dependent $(\%)$ & 41 & 57 & 50 & 38 \\
\hline Irregular bowel pattern (alternating with diarrhoea) (\%) & 10 & 13 & 8 & 28 \\
\hline Excessive straining with defecation often $(\%)$ & 64 & 73 & 75 & 60 \\
\hline Frequent pain with defecation (\%) & 43 & 47 & 58 & 33 \\
\hline Stool often feel hard (\%) & 69 & 70 & 71 & 72 \\
\hline Incomplete evacuation often felt (\%) & 77 & 70 & 79 & 60 \\
\hline Self digitation necessary (\%) & 56 & 53 & 42 & 42 \\
\hline Over $10 \mathrm{~min}$ needed to defecate $(\%)$ & 54 & 60 & 62 & 40 \\
\hline Position other than sitting to defecate often (\%) & 26 & 20 & 21 & 8 \\
\hline Anal blockage often sensed (\%) & 29 & 47 & 42 & 27 \\
\hline Unable to expel enema fluid $(\%)$ & 50 & 67 & 58 & 53 \\
\hline Laxatives used in childhood (\%) & 30 & 27 & 25 & 23 \\
\hline Constipation since childhood $(\%)$ & 47 & 50 & 50 & 45 \\
\hline Stay in hospital for colon blockage from constipation (\%) & 29 & 27 & 29 & 25 \\
\hline Constipation since childbirth (\%) & 33 & 40 & 17 & \\
\hline Stools change during menstrual cycle (\%) & 27 & 13 & 17 & 18 \\
\hline Rectal pain $\geqslant 1 /$ week $(\%)$ & 26 & 33 & 29 & 25 \\
\hline Manning criteria for IBS $\geqslant 2(\%)$ & 64 & 50 & 62 & 57 \\
\hline
\end{tabular}

$\mathrm{IQR}=$ interquartile rante, $\mathrm{IBS}=$ irritable bowel syndrome.

constipation category. Adjusting for age and sex, patients with slow transit constipation were significantly more likely than patients with normal transit constipation to have a regular defecation pattern, utilise different positions to defecate, and have sensations of incomplete evacuation, but none of the other clinical variables evaluated were significant discriminators. On the other hand, a sensation of anal blockage during defecation was significantly more frequent in the pelvic floor dysfunction group compared with the slow or normal transit constipation groups adjusting for age and sex. With the $\alpha$ value set, however, at 0.017 to adjust for multiple analyses, none of the symptoms were significant discriminators.

\section{COLONIC TRANSIT}

Table III shows a summary of the segmental colonic transit times. Total transit time was not considered in the analyses as it was used to help define the patient subgroups. When segmental transit times were examined, significant differences were detected overall between the groups. Rectosigmoid transit but not right or left colonic transit was significantly more delayed in pelvic floor dysfunction compared with normal transit constipation. Right and left but not rectosigmoid transit was significantly more delayed in slow transit constipation $v$ pelvic floor dysfunction; all segmental transit times were significantly more delayed in slow $v$ normal transit constipation (all $\mathrm{p}<0 \cdot 01$ ).

Rectosigmoid transit time at a sensitivity of $80 \%$ had a specificity of $83 \%$ for discriminating slow from normal transit constipation. For discriminating pelvic floor dysfunction from slow transit constipation, however, at a sensitivity of $80 \%$ the specificity of the rectosigmoid transit time was only $10 \%$. Similarly, for discriminating pelvic floor dysfunction from normal transit constipation, at a sensitivity of $80 \%$ the specificity of the rectosigmoid transit time was only $48 \%$.

\section{MULTIVARIATE ANALYSES}

Neither psychological scores or colonic symptoms were significant discriminators among subgroups of constipated patients using logistic regression analysis for the combined set of scores and symptoms. Similar results were obtained when the analysis was also adjusted for segmental transit times.

\section{Discussion}

We found that colonic and rectal symptoms could not discriminate among physiological subgroups of patients with severe idiopathic constipation. For example, a sensation of anal blockage during defecation was the only symptom that tended to be associated with pelvic floor dysfunction, but although this symptom

TABLE III Segmental colonic transit times.. Median time in hours (25th and 75th percentiles)

\begin{tabular}{|c|c|c|c|c|c|}
\hline & $\begin{array}{l}\text { Slow transit constipation } \\
(n=70)^{\star}\end{array}$ & $\begin{array}{l}\text { Pelvic floor dysfunction } \\
(n=30) \dagger\end{array}$ & $\begin{array}{l}\text { Slow transit and pelvic } \\
\text { floor dysfunction } \\
(n=24)^{\star} \dagger\end{array}$ & $\begin{array}{l}\text { Normal transit } \\
\text { constipation } \\
(n=60)^{\star}\end{array}$ & $\begin{array}{l}\text { Overall } \\
\text { comparison } n^{\star \star} \\
p\end{array}$ \\
\hline $\begin{array}{l}\text { Right colon } \\
\text { Left colon } \\
\text { Rectosigmoid } \\
\text { Total }\end{array}$ & $\begin{array}{c}27 \cdot 6(15 \cdot 6,36 \cdot 0) \\
37 \cdot 1(25 \cdot 2,55 \cdot 2) \\
32 \cdot 4(22 \cdot 8,48 \cdot 0) \\
106 \cdot 5(87 \cdot 6,130 \cdot 0)\end{array}$ & $\begin{array}{l}15 \cdot 0(4 \cdot 8,26 \cdot 4) \\
17 \cdot 4(9 \cdot 6,32 \cdot 1) \\
21 \cdot 6(12 \cdot 0,42 \cdot 0) \\
61 \cdot 8(36 \cdot 0,112 \cdot 0)\end{array}$ & $\begin{array}{c}36 \cdot 6(21 \cdot 1,43 \cdot 1) \\
38 \cdot 4(28 \cdot 8,57 \cdot 6) \\
30 \cdot 0(20 \cdot 0,52 \cdot 2) \\
115 \cdot 3(97 \cdot 2,129 \cdot 7)\end{array}$ & $\begin{array}{l}10 \cdot 8(6 \cdot 0,19 \cdot 0) \\
18 \cdot 0(11 \cdot 4,25 \cdot 2) \\
12 \cdot 5(6 \cdot 0,17 \cdot 4) \\
48 \cdot 0(33 \cdot 6,61 \cdot 2)\end{array}$ & $\begin{array}{l}<0.001 \\
<0.001 \\
<0.001 \\
\quad-\end{array}$ \\
\hline
\end{tabular}

${ }^{\star}$ Defined by total colonic transit times; ${ }^{\star \star}$ results of one-way Kruskal-Wallis (non-parametric) comparison among all four groups; $†$ defined by pelvic function testing (see text)

Pairwise comparisons (at $\alpha=0.008$ to adjust for six pairwise comparisons): slow transit constipation $v$ pelvic floor dysfunction - right colon, left colon significant; slow transit constipation $v$ normal transit constipation - right colon, left colon, rectosigmoid significant; pelvic floor dysfunction $v$ normal transit constipation rectosigmoid only significant; slow transit and pelvic floor dysfunction combined $v$ normal transit constipation - right colon, left colon, rectosigmoid significant; slow transit and pelvic floor dysfunction combined $v$ slow transit constipation - none significant; slow transit and pelvic floor dysfunction combined $v$ pelvic floor
dysfunction - right colon, left colon significant. 
was reported by $67 \%$ of patients with pelvic floor dysfunction, it was also reported by $50 \%$ of patients with slow transit and 53\% with normal transit constipation. Similarly, the Manning criteria for the irritable bowel syndrome ${ }^{21}$ failed to be of discriminatory value in identifying normal transit constipation from other types; indeed, typical irritable bowel syndrome symptoms were reported by $50 \%$ or more of patients in each of the constipation subgroups.

Two studies have suggested that constipated patients with normal transit times have more psychopathology than those with delayed transit times, ${ }^{78}$ although psychological profiles were not found to correlate with anorectal sensory or motor function. ${ }^{8}$ For example, Wald et al detected significantly higher scores on all scales of the SCL-90-R except obsessivecompulsion in patients with normal transit compared with those with slow transit constipation. Our results confirmed that patients with normal transit constipation suffered from more depression than patients with either slow transit constipation or pelvic floor dysfunction, but the other subscales were not significant and the actual differences were comparatively small. Moreover, we saw only a very modest negative correlation between colonic transit time and overall psychological distress (as measured by the GSI). We suggest therefore that measurement of psychological factors is probably not helpful in identifying individual patients with different types of constipation.

Pezim et al ${ }^{11}$ found that constipated patients with an immobile perineum had increased rectosigmoid transit times but normal right and left colonic transit times. Moreover, distal transit marker delay correlated with a history of facilitated defecation. Wald et $a l^{8}$ on the other hand, reported no change in segmental or total colonic transit times in patients with a history of obstructed defecation. Our study showed that rectosigmoid transit times were of little practical use in identifying pelvic floor dysfunction. Thus, at a sensitivity of $80 \%$, the specificity was only $48 \%$ using rectosigmoid transit to discriminate patients with recorded pelvic floor dysfunction from those with normal colonic transit. We conclude that in constipated patients suspected of having outlet obstruction, rectosigmoid transit delay alone provides insufficient evidence to make the diagnosis. Likewise, if distal transit is normal, this cannot rule out a diagnosis of outlet dysfunction. Physiological testing of patients with intractable constipation thus remains essential to identify pelvic floor dysfunction.

The limitations of this study need to be considered. We evaluated, retrospectively, only patients referred to a tertiary centre because no readily identifiable cause for chronic constipation had been found and conventional treatment modalities had failed. Therefore, our population is probably not at all similar to patients seen by general practitioners. The possibility of response bias also needs to be considered. Even though we achieved an overall response rate of $67 \%$, we cannot exclude the possibility that non-responders may have different psychological or clinical profiles. While we were careful to use strict criteria defined a priori for the subgrouping of patients, and even though this study represents one of the largest series yet reported, it is still possible that if the sample sizes had been greater, more striking differences in clinical and psychological variables would have been evident.

In conclusion, our findings suggest that clinical symptoms and psychological variables cannot discriminate among categories of severe idiopathic constipation. Extensive physiological testing therefore remains the optimal method of evaluation when management strategies for patients with severe intractable constipation are being planned. ${ }^{322}$

This work was presented in part at the American Gastroenterological Association meeting in Boston in 1993, and was published as an abstract (Gastroenterology 1993; 104: A514).

1 Talley NJ, Zinsmeister AR, Van Dyke C, Melton LJ III. Epidemiology of colonic symptoms and the irritable bowel syndrome. Gastroenterology 1991; 101: 927-34.

2 Kamm MA. Pathophysiology of constipation. In: Phillips SF, Pemberton JH, Shorter RG, eds. Physiology, pathophysiology and disease. New York: Raven Press, 1991: physiology

3 Pemberton JH, Rath DM, Ilstrup DM. Evaluation and surgical treatment of severe chronic constipation. Ann Surg 1991; 214: 403-11.

4 Tucker DM, Sandstead HH, Logan GM, Klevay LM, Mahalko J, Johnson LK. Dietary fiber and personality factors as determinants of stool output. Gastroenterology 1981; 81: 878-83.

5 Walker EA, Roy-Byrne PP, Katon WJ. Irritable bowel syndrome and psychiatric illness. Am f Psychiatry 1990; 147: 565-72.

6 Young SJ, Alpers DH, Norland CC, Woodruff RA. Psychiatric illness and the irritable bowel syndrome. Practical implications for the primary physician. Practical implications for the

7 Wald A, Burgio K, Holeva K, Locher J. Psychological evaluation of patients with severe idiopathic constipation: which instrument to use. Am $\mathcal{F}$ Gastroenterol 1992; 87: 977-80.

8 Wald A, Hinds JP, Caruana BJ. Psychological and physiological characteristics of patients with severe idiopathic constipation. Gastroenterology 1989; 97: 932-7.

9 Metcalf AM, Phillips SF, Zinsmeister AR, MacCarty RL, Beart RW, Wolff BG. Simplified assessment of segmental colonic transit. Gastroenterology 1987; 92: 40-7.

10 Bouchoucha M, Devroede G, Arhan P, Strom B, Weber J, Cugnenc P-H, et al. What is the meaning of colorectal tran-
sit time measurement? Dis Colon Rectum 1992; 35: 773-82.

11 Pezim ME, Pemberton JH, Levin KE, Litchy WJ, Phillips SF. Parameters of anorectal and colonic motility in health SF. Parameters of anorectal and colonic motility in health and in sev.

12 Chaussade S, Khyari A, Roche H, Garret M, Gaudric M, Couturier $\mathrm{D}$, et al. Determination of total and segmental colonic transit time in constipated patients. Results in 91 patients with a new simplified method. Dig Dis Sci 1989; 34: 1168-72.

13 Talley NJ, O'Keefe EA, Zinsmeister AR, Melton LJ III Prevalence of gastrointestinal symptoms in the elderly: a population-based study. Gastroenterology 1992; 102: 895-901.

14 Talley NJ, Phillips SF, Melton LJ III, Wiltgen C, Zinsmeister AR. A patient questionnaire to identify bowel Zinsmeister AR. A patient questionnaire to

15 Talley NJ, Phillips SF, Wiltgen CM, Zinsmeister AR, Melton LJ III. Assessment of functional bowel disease: the bowel LJ III. Assessment of functional bowel disease: the bowel

16 Thompson WG, Heaton KW. Functional bowel disorders in apparently healthy people. Gastroenterology 1980; 79: 283-8

17 Sandler RS, Drossman DA, Nathan HP, McKee DC. Symptom complaints and health care seeking behaviour in subjects with bowel dysfunction. Gastroenterology 1984 87: 314-8.

18 Swedlund J, Sjodin I, Dotevall G. GSRS-A clinical rating scale for gastrointestinal symptoms in patients with irritable bowel syndrome and peptic ulcer disease. Dig Dis $\mathrm{Sci}$ 1988; 33: 129-34.

19 Proano $M$, Camilleri M, Phillips SF, Brown ML Thomforde GM. Transit of solids through the human Thomforde GM. Transit of solids through the human colon: regional quantification in the

20 Stivland T, Camilleri M, Vassallo M, Proano M, Rath D, Brown $\mathrm{M}$, et al. Scintigraphic measurement of regional gut transit in idiopathic constipation. Gastroenterology 1991; 101: 107-15.

21 Talley NJ, Phillips SF, Melton LJ III, Mulvihill C, Wiltgen C, Zinsmeister AR. Diagnostic value of the Manning criteria in irritable bowel syndrome. Gut 1990; 31: 77-81.

22 Wexner SD, Daniel N, Jagelman DG. Colectomy for constipation: physiologic investigation is the key to success. Dis Colon Rectum 1992; 35: 235-7. 